MORE PEAT PLANTS AND A GOOD MARKET.

The total number of plants at which peat was commercially produced in 1918 was twenty-five, an increase of seven over the number operating in 1917. All the plants that operated in 1917, except four, contributed to the output in 1918, besides eleven that were not operating in 1917. The plants known to be operating in 1918 were distributed as follows: New York and New Jersey, 4 each; Massachusetts, 3; Georgia, Illinois, Indiana, and California, 2 each; Maine, New Hampshire, Connecticut, Pennsylvania, North Carolina, and Florida, 1 each. Nearly all the producers reported that the demand for peat exceeded the supply, and some stated that on account of limited facilities they were unable to fill the orders of their regular customers.

\title{
CHEMICAL PHYSIOLOGY.
}

By L. J. Hendenson, Harvard University.

Great men of vision have known for a Iong time, say more than fifty years, that there is a science of general physiology which is the study of the fundamental activity of all living things, regardless of animals or plants, and that is largely a chemical matter that science is just beginning. The chemical department and the chemist of the country need help in the new development of biology. There is coming to be, in this way, some consolidation of all the sciences, and a larger and more important activity on the part of chemistry.

As a specific case of what chemistry may do, I would like to cite the example of Pasteur. It is not generally realized that Pasteur was a chemist and was never, all his life long, really a biologist. Men trained in his own school in Paris say as much. He never really learned to think biology, but he had the chemical training. He was primarily a chemical investigator, and he attacked practical problems and solved them. It happened to be the most important problem for human welfare.

There are situations growing out of chemistry, which are coming to underlie biology and they are going to be developed in every way. Chemistry is the thing that is of growing importance at this moment.

\section{UNEXPLORED FIELDS IN CHEMISTRY.}

By T. W. RICHARDs, Harvard University.

We are only at the beginning of the understanding of the mechanism of chemical action. There are a great many things about it we do not know. We know oxide will combine with sodium and not with fluid. We may never find out why, but shall certainly find out more than we know at present. And it is the task primarily of the professors in the institutes of higher learning of the world to make these discoveries. Because of necessity, the interests of men who are working on the particular side of things, the application of those things which have already been discovered, are centered in other aspects of the subject. Fariday, when he made those experiments with waters and magnets which laid the basis of the dynamo, had no conception whatever of the power of the Niagara of previous years, and did not dream of it making such a rumpus. What he did was to discover the laws which determine electric induction. The same way in chemistry; it is a newer science than physics and has not got quite so far. It has not yet reached the highest state. Chemistry has things like that in the future. Chemistry holds the possibility of supplying energy, of continuing to build a scientific basis for medicine, not only pathological, but especially physiological. 